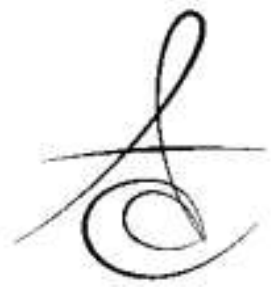

\title{
PERİODONTOLOJİDE DENEY HAYVANI VE HASTALIK MODELLERİ
}

\section{EXPERIMENTAL DISEASE AND ANIMAL MODELS IN PERIODONTOLOGY}

\author{
Dr. Öğr. ÜyesiMustafa Özay USLU* Arş. Gör. Dt. Ömer Alperen KIRMIZIGÜL*
}

\author{
Arş. Gör. Dt. Umut ÖĞÜTÜcü**
}

\author{
Makale Kodu/Article code: 3576 \\ Makale Gönderilme tarihi: 16.02.2018 \\ Kabul Tarihi: 20.04.2018 \\ DOI : $10.17567 /$ ataunidfd. 417173
}

\author{
M.Özay Uslu: ORCID ID: 0000-0002-9707-1379 \\ Ö.Alperen Kırmızıgül: $O R C I D I D$ : 0000-0001-5828-8949 \\ Umut Öğütücü: ORCID ID: 0000-0001-8519-1827
}

\section{ÖZ}

Deney hayvanları, araştırmalarda ve biyolojik testlerde ilaç, madde, tedavi gibi etkinliklerin, canlı organizmadaki sonuçlarının elde edilmesi için kullanılan hayvanlardır. Deney hayvanlarının bilimsel deneylerde kullanılmaya başlamasıyla birlikte araştırma verilerinin istenildiği kadar tekrarlanabildiği ve istenen koşullar da yeniden elde edilebildiği görülmüştür. Bu hayvanlar sağlık bilimleriyle ilgili birçok biyolojik testte kullanılabildiği gibi diş hekimliği araştırmalarında da sıklıkla kullanılmaktadır. Hayvan çalışmaları periodontal araştırmalar için yeni tedavilerin denenmesi öncesinde tamamlayıcı özelliktedir. Hayvan modelleri hipotezlerin doğrulanmasını mümkün kılmalı ve yenilenen yaklaşımların güvenilirliğini ve etkinliğini ispatlamalıdır. Uygun hayvan modelinin seçimi periodonsiyumun ve hastalığın doğasının insanlardakine benzerliğine bağlıdır. İnsanlardaki periodontitisi modellemek için; kemirgenler, köpekler, insan olmayan primatlar, tavşanlar gibi farklı türlerde birçok hayvan modeli kullanılmışır. Ancak her deney hayvan modelinin kendine özgü avantaj ve dezavantajı bulunmaktadır. Her bir türün, farkı beslenmeleri, ömrü, doku yapısı, alışkanlıkları, genetik özellikleri ve konak savunma mekanizmaları olduğundan uygun deneysel modeli belirleyebilmek zorlaşabilmektedir. Araştırmacı deney hayvan modelini oluştururken planladığı çalışmaya uygun hayvanı ve defekt modelini seçebilecek bilgiye sahip olmalıdır. Çalışılacak hayvanın özellikleri dikkatle incelenmelidir. Bu derlemenin amacı periodontoloji alanındaki araştırmalar için en uygun hayvan ve hastalık modelini tanımlamaya yardımcı olmaktır.

Anahtar Kelimeler: Deney hayvanları, hastalık modelleri, defekt modeli

\section{ABSTRACT}

Experimental animals were used for obtaining results in living organisms of activities such as medication, substance and treatment in research and biologic tests. It is seen that research data as well as desired conditions can be repeated and obtained as much as required since the beginning of use of experimental animals in scientific experiments. While these animals can be used in many biologic tests related to health sciences, they are also frequently used in dental research. Animal studies are complementary before testing new therapies for periodontal investigations. Animal models should allow validation of hypothesis, and prove reliability and efficiency of new approaches. Selection of suitable animal model depends on similarity of nature of periodontium and the disease with those of human. Many animal models have been used in different species such as rodents, dogs, non-human primates, rabbits. However, each experimental animal model has specific advantages and disadvantages. Determining the suitable experimental model becomes difficult as each species has different nutrition, lifetime, tissue structures, habits, genetic features and host defense mechanisms. Researchers must have the adequate knowledge to select the suitable experimental animal and defect model. Characteristics of the animal to be studied should be carefully examined. The aim of this review is to help defining the most suitable animal and disease models for researches in periodontology.

Key Words: Experimental animals, disease models, defect models

* Department of Periodontology, Faculty of Dentistry, Inonu University, Malatya, Turkey

** Department of Periodontology, Faculty of Dentistry, Abant İzzet Baysal University, Bolu, Turkey

Kaynakça Bilgisi: Uslu MÖ, Kırmızıgül ÖA, Umut Öğütücü U. Periodontolojide Deney Hayvanı ve Hastalık Modelleri. Atatürk Üniv Diş Hek Fak Derg 2020; 30 : 148-155. Citation Information: Uslu MO, Kırmızıgul OA, Umut Oğutucu U. Experimental Disease and Animal Models in Periodontology. J Dent Fac Atatürk Uni 2020; 30: 148-155.

\section{GİRİ̧̧}

Periodontitis, dişi destekleyen tüm dokuları etkileyen, kronik inflamatuar bir dişeti hastalığıdır. Periodonsiyumun bu iltihabi hastalığı, dişeti doku- sunun, periodontal ligamentin ve destekleyici alveolar kemiğin progresif yıkımı ile sonuçlanmaktadır. Periodontal tedavinin amacını; periodontal dokuların cerrahi olmayan veya cerrahi tekniklerle, yönlendirilmiş doku rejenerasyonu için kullanılan biyomateryallerle, büyüme faktörletiyle, kemik greftleriyle veya son 
zamanlarda üzerinde çalışıldığı gibi mezenkimal kök hücrelerle rejenerasyonu oluşturmaktadır. Periodontoloji alanındaki deneysel araştırmalar kemik defektlerinin cerrahi olarak oluşturulması ve periodontitisin deneysel modelleri kullanılarak periodontal dokuların rejenerasyonunun sağlanması üzerine yoğunlaşmaktadır. ${ }^{1}$ Histolojik olarak dokuların incelenememesi ve yeni tedavi yaklaşımlarının yan etkilerinin bilinememesi gibi nedenlerden dolayı yeni tedavilerinin denenmesi, periodontal hastalığın başlangıcı ve ilerlemesinin incelenmesi insan üzerinde yapılamamaktadır. Deneysel çalışma modelleri, gerek hastalığın tanımlanmasında gerekse yeni tedavilerin ortaya konmasında yıllarca kullanılmıştır. ${ }^{2,3}$

Hayvan çalışma modellerinin sağladığı prospektif çalışma imkanı, hastalığın birçok yeni özelliğinin ortaya çıkmasına yardımcı olmakta, yeni tekniklerinin etkinliğini ve güvenirliğini ortaya koymaktadır. Yeni aparey veya ilacın insanlarda kullanılmadan önce yaşayan bir sistemde denenmesi yasal olarak zorunluluktur. Her hayvan türünün fizyolojik ve anatomik özelliklerinin farklı olması nedeniyle her çalışmaya uygun olmamalarından dolayı, araştırmacı çalışmasının başında çalışacağı hayvanı ve defekt modelini seçerken dikkatli olmalıdır., ${ }^{1,4}$

\section{Defekt Oluşturulması}

Hayvan çalışmalarında kulanılan 4 çeşit defekt modeli mevcuttur. Bunlar;

- Doğal defekt modeli

- Akut defekt modeli

- Kronik defekt modeli

- Akut/Kronik defekt modeli

Doğal defekt modeli: Deney için kullanılan hayvanlarda doğal yollardan hastalık oluşumunun beklendiği defekt modelidir. ${ }^{5}$ Hayvanlarda doğal yollardan periododontitis oluşumunun sadece ileri yaşlarda görülmesinden ve oluşan lezyonların genellikle asimetrik olmasından dolayı nadir olarak kullanılan bir modeldir. ${ }^{2}$

Akut Defekt modeli: Bu modelde defekt doğrudan oluşturulmaktadır. Mukoperiostal flep açıldıktan sonra kemik, periodontal ligament ve sement istenen defekt boyutuna uygun olarak şekillendirilmekte ve flep kapatılmaktadır. ${ }^{5}$ Akut defekt modelinde, defekt oluşumu için beklenmemesinden dolayı kazanılan zamanın, maliyetin düşük olması ve defekt araştırmacı tarafından oluşturulduğu için bilateral olarak eşit defektler oluşturulabilmesi avantajları arasında sayılabilmektedir. Özellikle periodontal rejenerasyon konulu çalışmalarda öngörülebilir bir çalışma modeli olmasının yanında farklı tekniklerin, cihazların ve ilaçların iyileşmeye etkisinin incelendiği çalışmalarda akut defekt modeli tercih edilebilir. ${ }^{1}$

Kronik Defekt Modeli: Kronik modelde plak oluşumunu ve kemik yıkımını arttıracak materyaller diş çevresine yerleştirilerek defekt oluşumu hedeflenmektedir. Kullanılan ligatürler dişin çevresine ya da gingival marjinin hafif apikaline yerleştirilip, plak kaynaklı inflamasyonun zamanla apikale doğru ilerleyerek çevre dokularda yıkıma neden olması sağlanmaktadır. ${ }^{5}$ Kronik defekt modelinde büyük bir avantaj olarak spontan bir rejenerasyon görülmemektedir. Defektin kendiliğinden kapanma intimali bulunmamakta, ancak derin bir cep ve kemik kaybı yaklaşık 3-6 ayda elde edilebilmektedir. Bu çalışma modelinde interproksimal alanlarda derin defektler elde edilebilirken; fasial ve lingual yüzeyde daha sığ defektler elde edilebilmektedir. Bu model interproksimal defektler için daha uygun görülmektedir. ${ }^{2}$ Ligatürlerin tek köklü ve konik dişlerde daha hızı yıkım sağladığı bildirilmiştir. ${ }^{6}$

Akut/Kronik Defekt Modeli: Akut kronik defekt modelinde periodontal defekt istenilen yerde cerrrahi olarak oluşturulup flep kapatılmadan önce kronik enflamasyonu uyarmak için bölgeye yabancı cisim yerleştirilmektedir. Bölgedeki spontan iyileşmenin önüne geçilmesi için uygulanan cisimlerin defekt bölgesine uyumlu olması gerekmektedir. Defekt oluşturulduktan 6 hafta sonra bölgeye yerleştirilen cisimler çıkartılırken, bölgeye plak retansiyonu için ligatürler yerleştirilmektedir. Ligatürlerin yerleştirilmesinden sonra, istenen inflamasyon durumuna göre, 5-6 hafta sonra defekt deneye hazır hale gelebilmektedir. Çalışma süresinin kısa olması ve akut defekt modelinin avantajlarını içermesi sebebiyle günümüzde en sık kullanılan yöntem olarak dikkat çekmektedir. ${ }^{7}$

\section{Fareler}

Farelerin diş formülü tipik bir kemirgen dentisyonudur: Keser(I) 1/1, Kanin(C) 0/0, Premolar(Pm) $0 / 0$, Molar(M) 3/3. Farelerde erüpsiyon hayat boyu devam etmektedir. Düzenli mezializasyon nedeniyle molar bölgesinde krater şeklinde kemik defekleri oluşmasından dolayı insan periodontitisine benzer şekilde, yaşla artan oranlarda yaklaşık 9. aydan başlayarak periodontitis geliştirebilmektedirler. Doğal olarak veya indüklenmiş periodontal hastalıkları araştırmak için pek tercih edilmemektedirler. Fareler konak-parazit etkileşimini anlamak için kullanılabilirler. Bazı farelerde periodontal hastalığa genetik yatkınlık olduğu düşünülmektedir. ${ }^{8}$ 


\section{Ratlar}

Kemirgen tipleri içinde ratlar, periodontal fizyoloji ve periodontal hastalıkların patogenezi için sıklıkla kullanılan hayvan modeli olarak karşımıza çıkmaktadır. Tipik kemirgen dentisyonu: I 1/1, C 0/0, Pm 0/0, M $3 / 3$ 'tür. Kesici dişlerde sürekli erüpsyon izlenmektedir. Ratlarda diş etinin yapısı, sığ dişeti oluğuna sahip olmaları ve birleşim epitelin diş yüzeyine tutunması yönleriyle insanlardakine benzemektedir. ${ }^{9}$ Periodontal açıdan ele alındığında iki büyük farklılık bulunmakta olup, ilki ratlarda sulkus epitelinin keratinize olmasıdır. İkincisi ise dişeti, birleşim epiteli ve gingival epitelin en yüzeysel hücreleri ile birleşim epiteli hücreleri arasındaki bağlantı desmozomaldır. ${ }^{10} \mathrm{Bu}$ yapısal farklılığa rağmen birleşim epiteli insanlarda olduğu gibi, yabancı maddeler, bakteriyel endotoksinler ve inflamatuar hücre eksüdaları için bir yol gibi gözükmektedir. ${ }^{11-14} \mathrm{Bu}$ nedenle yapısal farklılıklar çalışmalar için bir engel teşkil etmemektedir.

Dentisyondaki fizyolojik değişiklikler kemirgenin ömrü boyunca devam etmektedir. Oklüzal yüzeylerdeki aşınmalar ile kemik ve semetteki apozisyonlar sebebiyle dişler devamlı sürmeye devam etmektedir. ${ }^{10}$ Periodontal lezyonlar ön dişlerdeki devamlı sürme nedeniyle genellikle molar dişlerde görülmektedir. ${ }^{2}$ Her dişte birbirinden bağımsız bir hipersementoz görülürken, özellikle devamlı olarak oklüzal-distal-bukkal yönde hareket eden molarlarda, diş pozisyonunda ilerleyici değişiklikler meydana gelmektedir. ${ }^{10}$ Ratlarda oral hastalıkların araştırılmasına yönelik en başarılı yaklaşımlardan biri olarak, gnotobiyotik veya germ-free ratların kullanımı gösterilmektedir. Prophyromonas gingivalis, Aggregatibacter actinomycetemcomitans, Fusobacterium nucleatum, Capnocytophaga, Eikenella corrodens, Actinomyces viscosus ve Streptococus sobrinus gibi çeşitli bakterilerin aşılanması veya enjeksiyonu periodontal lezyonların oluşmasını sağlayabilmektedir. ${ }^{15}$ Ratlarda periodontal hastalık oluşturmak için ligatür bağlama, diyet ve bakteri aşılanması gibi birçok yol mevcuttur. ${ }^{7}$ Ratlarda periodontal hastalık insanlardan farklı olarak seyretmektedir. Mikroorganizmaların germ-free ratlara inoküle edilmesinden sonra, periodontal yıkım çok hızı gerçekleşmekte olup bu durumda ligatürlerle hastalık oluşturmaya gerek kalmamaktadır. Kemik rezorpsiyonu, başlandıktan sonra insanlarda olduğu gibi sporodik olarak değil, sürekli olarak gerçekleşmektedir. ${ }^{16}$

Diş taşı formasyonu, diyetlerinin uygun olduğu düşünüldüğü için farklı rat türlerinde çalışılabilmektedir. ${ }^{17}$ Sakkarozdan zengin bir diyetle beslenen ratlar- da, molar fissürlerde, interdental boşluklarda ve serbest dişeti kenarında, çoğunlukla gram-pozitif bakteri plaklarının hızla proliferasyonu ve büyümesi görülmekte ve bu durum sonuçta yuvarlak ya da krater gibi diş eti ceplerine yol açmaktadır. Bu nedenle doğal defekt modeli ratlar için, diş taşı ve çürükleri inceleme konusunda kabul edilebilir bir model olurken, periodontal hastalıklar için çok da uygun olmamaktadır. Rat ve insan periodontal hastalığı arasındaki bir diğer fark da lokalizasyonlarında görülmektedir. İnsan dişlerinde lezyonlar kök yüzeyi boyunca uzanırken ratlarda lezyonun apikal seviyesi interdental dokuların orta kısmı boyunca yerleşik görünmektedir. Kemik kaybı, birleşim epitelinin apikale göçü olmaksızın oluşabilmektedir. ${ }^{18}$ İlgili dişetinin yanıtı, akut, kronik olmayan, immün bir sızıntı şeklinde gözlemlenmektedir. ${ }^{19}$ Bazı rat türleri periodontal hastalığa oldukça dirençli olup, periodontitis oluşumunun ancak yaşam döngüsünün ilerleyen safhalarında kendiliğinden görülebilmesinden dolayı, bu ratlarda daha çok spesifik bakteri inokülasyonları ile çalışılması gerekmektedir. ${ }^{6}$

Ratlarda özel bir akut model ile çalışılmaktadır. $\mathrm{Bu}$ model cerrahi olarak ikinci mandibular molar dişlerin kök yüzeylerinde fenestrasyon şeklinde bir periodontal defekt oluşturmasıdır. Ratlarlarda oluşan defektler bu cerrahi modelde Huan tarafından hem derinlik $(1.5 \mathrm{~mm})$ hem de genişlik $(3 \mathrm{~mm}$ ) açısından standardize edilmiştir. ${ }^{20}$ Ratlar aynı zamanda mine matris türevlerinin kullanımından sonra supra ve intraosseöz kusurların iyileşmesini değerlendirmek için kullanılmıştır. ${ }^{21,22}$ Keser diş ile birinci molar arasındaki dişsiz alveol kreti veya mandibulanın kenarı da yönlendirilmiş kemik rejenerasyonuna uygun cerrahi modeller olarak değerlendirilmektedir. ${ }^{23,}{ }^{24}$ Ayrıca rat tibiasında kemik iyileşmesi üzerinde yapılan çalışmalar bulunmaktadır. Ratlar deneysel araştırma için kabul gören hayvanlardır. Yetiştirme ve barınma masrafları nispeten düşük olduğundan, istatistiksel analiz için yeterli sayıdaki çalışmaları yapmak mümkün olmakla birlikte, sürekli oklüzal erüpsiyon görülmesi ve diş kökleri üzerindeki kemik mukavemetinin düşük olması; sonuçların modellenmesini ve analizini zorlaştırmakta ayrıca kayda değer önyargılara neden olabilmektedir.

\section{Hamsterler}

Hamsterlar da diğer kemirgenlerle aynı diş formülüne sahiptir: : I 1/1, C 0/0, Pm 0/0, M 3/3. Hamsterlar ağızlarını neredeyse 180 derece açabilmekte ve oklüzal aşınmaları diğer kemirgenlere göre çok daha az olmaktadır ${ }^{5}$. Hamsterlarda periodontal hastalık kendiliğinden oluşmaz ancak deneysel olarak yalnızca birkaç 
türde elde edilebilmektedir. ${ }^{25}$ Periodontal hastalık, yüksek konsantrasyonlarda karbonhidrat, özellikle sükroz içeren uygun bir diyet kullanılarak elde edilebilmektedir $^{26}$. Enflamatuar yanıt hamsterlarda çok sınırlıdır. Diyet bağımlı periodontal lezyonları olan hamsterlarda alveolar kemik rezorpsiyon mekanizmaları, gram pozitif bakteriler ile enfekte ratlarda görülen mekanizmalara oldukça benzemesine rağmen interdental septumun ratlara göre dar olması sebebiyle kemik içi defekt görmek mümkün olmamaktadır. ${ }^{2}$ Hastalık diş eti çekilmesi ve horizontal kemik kaybı şeklinde ilerlemektedir. ${ }^{27}$

Hamsterlar başlıca iki konuda tercih edilmektedir; ilk olarak kariyojenik mikroorganizmaların bol miktarda plak oluşturması ve çürük lezyonlarını hızla geliştirebilmeleri nedeniyle öncelikle çürük araştırmalarında, ikinci olarak başlarının her iki yanında tabakalı skuamöz epitel ile kaplanmış bukkal torbalar olması nedeniyle ağız karsinomu araştırmalarında. ${ }^{5}$

\section{Vizonlar}

Yetişkin vizonun diş formülü I 3/3, C 1/1, Pm $3 / 3$ ve $M 1 / 2$ 'dir. Vizonlarda yaş ve plak ile ilişkili spontan periodontitis gözlemlenebilmektedir. Bu periodontal hastalığın derecesi yalnızca çok yaşlı hayvanlarda şiddetli gibi gözükmektedir. Vizonlarda Chediak Higashi Sendromuna(C-HS) genetik yatkınlık bulunmaktadır. Sendromlu vizonlarda nötrofiller, kemotaktik yanıttaki eksiklikler ve lizozomal enzimlerin periodontal dokuya kitlesel salınımı nedeniyle periodontal yıkım çok daha hızı ve agresif olmaktadır. Bu vizonlar çok daha erken dönemlerde dişlerini kaybetmektedir. Bu nedenle, özellikle sendromlu vizonlar, periodontal hastalıkların etiyolojisinin araştırımasında uygun deneysel model olabilirler ancak barınma sorunu sebebiyle son yıllarda ki çalışmalarda bu modellere pek rastlanmamaktadır. ${ }^{2}$

\section{Feretler}

Feretlerin geçici ve daimi dentisyonu vardır. Diş formülasyonları I 2/2, C 1/1, Pm 4/4, M 2/2'dir. Ferretler doğal olarak insanlara benzer diş taşı ve periodontal hastalık geliştirmektedir. Periodontal lezyonların gelişim süreçleri, insanlarda gözlemlenenle oldukça benzemektedir. Hastalık ilerledikçe, diş taşının hem miktarı hem de büyümesi artmaktadır. ${ }^{28,}{ }^{29}$ Dişeti enflamasyon belirtileri gösterebilmektedir. Kemirgenlerin aksine, feretlerde taş oluşumu diyete bağlı değildir ve canlı feretlerde skorlanabilmektedir. Feretler, diş taşı incelemek için uygun modeller olarak değerlendirilmektedirler. Feretlerde diş taşı, hidroksiapatite benzer fiziksel bir yapıya sahiptir. Feret ve insan diş taşı arasındaki temel fark, feretlerde taşın daha az miktarda kalsifikasyona uğramasıdır. Feretlerin standart kafeslerden kolayca kurtulabilmeleri ve özel bakıma intiyaç duymaları dezavantajları olarak görülmektedir. ${ }^{2}$

\section{Köpekler}

Köpekler küçük boyutta olmaları ve çalışma kolaylığı nedeniyle periodontolojide yapılmış hayvan çalışmalarında çok tercih edilmişlerdir. Köpekler diphidont şekilde dişlenirler. Diş dizisi I 3/3 C 1/1Pm 4/4 M 2/3 şeklindedir. Köpekler ve insanların periodontal yapılarında belirgin birkaç farklılık bulunmaktadır. Sağlıklı köpeklerde gingival sulkus ve dişeti oluğu sıvısı bulunmamaktadır. Oklüzal morfoloji ve diş taşı kompozisyonu insandakinden oldukça farklıdır. Ancak supragingival ve subgingival plak kompozisyonu, gingivitisin periodontise dönüşmesi, periodontitisin yaşla doğal olarak da görülmeye başlanması gibi ciddi benzerlikler de bulunmaktadır. Diş eti çekilmeleri ve periodontitis köpek yaşam döngüsünün doğal hastalıklarıdır.

Köpekler sıklıkla biyomateryal ve implant uygulamaları, periodontal ve mukogingival cerrahi denemeleri gibi işlemler için kullanılmaktadır. Köpeklerde premolar dişlerin anatomisi sayesinde Sınıf III Furkasyon defektlerinin çok daha sık görüldüğü gözlenirken sınıf II furkasyon defektleri çok nadir olarak gözlenmektedir. Köpek çalışmalarının maliyeti ratlara ve tavşanlara göre yüksekken primatlara göre oldukça düşüktür. Köpeklerde kemiğin iyileşme hızının primatlara göre \%30 daha hızlı olduğu görülmektedir. ${ }^{2,5}$

\section{Koyunlar}

Diphidont dişlenme geçirirler. Koyun daimi dentisyonu 32 dişten oluşur: I 0/3, C 0/1, Pm 3/3, M $3 / 3^{2}$ Keser dişlerin kökleri çok kısadır ve fizyolojik olarak hareketlidirler. Periodontitis, bu anterior dişleri etkileyebilmekte ve derin periodontal ceplere şiddetli kemik kaybı eşlik edebilmektedir. Histolojik olarak, cep duvarı tipik bir cep epiteli ile çevrili bulunmaktadır. Cebin tabanında, birleşim epiteli çok kısadır ve bağ dokusu apikal plak sınırına göç eden nötrofiller tarafından infiltre edilebilmektedir. ${ }^{30}$ Dişeti iltihabı orta şiddette seyretmektedir. ${ }^{1}$ Koyunlarla ilgili periodontal çalışmalar son yıllarda giderek artmaktadır. Koyun kadavralarına olan ulaşımın kolaylığı nedeniyle periodontal cerrahi pratiklerinde, implant çalışmalarında ve periodontal cerrahi materyallerinin test edilmesinde sıklıkla kullanılmaktadırlar.

\section{İnsan Olmayan Primatlar}

İnsan olmayan primatlarda filogenetik yakınlık kaynaklı oral yapı oldukça benzerlik göstermektedir. 
Diş yapıları benzerlik gösterse de dişler insan dişine göre çok daha küçüktür. İnsanlar gibi diphidont dişlenme gözlenir ve diş dizi formülleri aynıdır. Sağlıklı diş eti yapısını insan diş eti yapısından histolojik olarak ayırt etmek mümkün gözükmemektedir. Primatların birçok türü bulunmaktadır. Çalışmaya göre çalışılacak tür dikkatli seçilmelidir. Primatların bazı türlerinde (özellikle büyük olanlar) yaşamın ilerleyen evrelerinde doğal olarak plak, diş taşı ve mikrobiyal patojenler görülmektedir. Primatlardaki gingivitis periodontitis değişimi insanlara oldukça benzerlik göstermektedir. Doğal modelle oluşan defektler genellikle asimetriktir gelişmektedir. Özellikle babunlardaki periodontal hastalık klinik ve mikroskobik olarak insanlardakine yüksek benzerlik göstermektedir. Primatlarda periodontal cerrahinin tüm aşamaları çalışılabilmektedir. Özellikle sınıf II furkasyon defektleri için primatlar çok iyi modeller oluştururken sınıf III furkasyon defektlerine çok nadir olarak rastlanmaktadır. Primatların en büyük dezavantajları maliyetlerinin yüksek oluşu ve elde edilmelerinin güç olmasıdır. Doğadan elde edilenlerinde Mycobacterium tuberculosis, Herpes tip B, Simian B gibi patojenlere rastlanmaktadır. ${ }^{1,2}$

\section{Tavşanlar}

Oral mikroorganizmaların tavşanlardaki karakterizasyonu insan florası ile uyumlu olması dikkat çekmektedir. Tavşan florasında F. nucleatum, S. milleri grubu, $A$. israelii ve $A$. haemolyticum da dahil olmak üzere çok sayıda patojen bakteri gösterilmiştir. ${ }^{31}$ Tavşanlar, cerrahi olarak indüklenen periodontal defektlerin oluşturulması ve periodontal rejenerasyonun incelenmesi için kullanılmıştır. Tavşanlar ayrıca biyomateryalleri test etmek veya peri-implantitis tedavisinde kullanılmıştır. Tibia veya femur gibi uzun kemiklerde transkortikal drillenerek hazırlanan defekt modeli $^{32,33}$ periodontal hastalıkların spesifik durumundan çok uzaktır ancak kemik iyileşmesini test etmek için uygun bir model olarak görülmekte ${ }^{1}$, periodontal ligamentlerin rejenerasyonu için uygun bir çalışma modeli olarak görülmemektedirler. ${ }^{34}$

\section{Diğer Hayvanlar}

Periodontolojiye yönelik çalışmalarda yukarıda bahsedilen hayvanların dışında diğer hayvanlar olarak kediler, atlar ve minyatür domuzlar da bazen kullanımaktadır. Kediler bir çalışmada hayvan modeli olarak kullanılmıştır. Bu araştırmada cerrahi olarak sınıf III furkasyon defekti premolar seviyesinde oluşturulmuş periodontal iyileşme sırasında kök seviyesinde ankiloz incelenmiştir. ${ }^{35}$ Atlarda yaygın doğal olarak görülen ağız hastalıkları arasında bukkal aşınmalar, diş taşı, diş eti çekilmeleri ve periodontal cepler bulunmaktadır. Bir çalışmaya göre, periodontal cepler ve dişeti çekilme prevelansı yaşlı atlarda en yüksek seviyededir ve çoğunlukla diğer dental rahatsızlıklar ve diş kaybıyla ilişkilidir. ${ }^{36}$ Başlıca implant cerrahisi mine matris deriveleriyle periodontal rejenerasyon ve dental lazerlerin periodontal iyileşmeye etkisi üzerine beş mini-pig çalışması bulunmaktadır. ${ }^{\text {, }}$ 37, 38

\section{TARTIŞMA}

Her hayvanın sahip olduğu avantaj ve dezavantajların yanında çalışmaya uygun olan hayvan modelinin seçilmesi çalışmayı başarıya götüren en önemli etmenlerden biridir (Tablo 1). Çalışılacak konuya uygun olarak model seçilmediğinde ortaya çıkacak sonuç yanıltıcı olabilmektedir. Uygun model seçilirken modele erişim imkanı, maliyet, çalışma zorluğu göz önünde tutulmalı ve çalışmalarda mümkün olan en küçük ve en maliyetsiz hayvandan başlanması gerekmektedir. Çalışılan hayvanın gelişmişlik açısından insana yaklaşması çalışmanın anlamlıı̆̆ını arttırmaktadır. İnsan olmayan primatlar ve köpekler birçok konuda en uygun modeller olarak gözükse de çalışmanın etik problemleri, maliyetinin oldukça yüksek olması ve hayvanlara ulaşım zorluğu çalışmayı çok güç kılmaktadır. Etiyoloji ve hastalıkların altındaki mekanizma konusunda primat ve köpekler günümüzde hala çalışmalar için altın standart olarak görülmektedir. Özellikle beagle cinsi köpeklerde mekanizmalar üzerine son yıllarda birçok çalışma yapılmıştır. ${ }^{39-41}$ Tavşanlar, primatlara ve köpeklere göre çok daha çalışılabilir bir model olmasına rağmen implant dışında elde edilen sonuçlar insanlara çok benzer sonuçlar vermemektedir. İmplant cerrahisi ve osseointegrasyon çalışmaları için tavşan modelleri günümüzde kullanılan en verimli çalışma modelleri olarak değerlendirilmektedir. İmplant uygulamaları, osseointegrasyon, primer stabilite gibi faktörlerle model uygunluğu nedeniyle günümüzde sıklıkla tavşanlarda yapılmaktadır. ${ }^{42-44}$ Feretler özellikle diş taşı üzerinde yapılan çalışmalarda yüksek başarılı sonuçlar vermektedir. Diş taşı çalışmalarındaki tutarıılı̆ı köpekler kadar yüksek olmasının yanı sıra üretim zamanlarının çok daha kısa olması, etik ve maliyet açısından uygunluğu olası bir diş taşı çalışması için feretleri en uygun çalışma modeli olarak işaret etmektedir. Feretler dünyada diş taşı çalışmalarında sıkça kullanılsa da ${ }^{45}$ ülkemizdeki deney hayvanları merkezlerinde çalışımamaktadır. Ayrıca feretler sialolit çalışmaları için dünyada yaygın kullanılan modellerdir. $^{46}$ Ratlar ve hamsterlar incelenen modeller 
arasında en sık çalışılan hayvan modelleridir. Rat ve hamsterların bakterisiz ortamda spesifik türler olarak yetiştirilebilme avantajı mikrobiyoloji ve immünoloji çalışmaları için onları eşsiz kılmaktadır. En büyük avantajları maliyetleri, barınma maliyetlerinin diğer modellere göre oldukça düşük olmasıdır. Biomateryal çalışmalarında köpek ve primatlara olan erişim güçlüğü, tavşanların anatomik olarak başarılı bir model olmaması nedeniyle ratlar ön plana çıkmıştır. ${ }^{47,48}$ Günümüzde ratlarda furkasyon defektleri için spesifik modeller sunulmuştur. Bu modeller tanımlanmış ve başarısını ispat etmiştir. ${ }^{49}$ İmplant çalışamları için rat mandibulası uygun bir model değildir. Bu nedenle tavşan domuz gibi daha büyük hayvanlar çalışmalıdır. Ancak sistemik durumların implantlara etkisi incelendiği durumlarda tibiaya mini implant yerleştirildiği rat çalışma modelleri mevcuttur. ${ }^{50}$ Ancak bu çalışma modellerinde ağız ortamı taklit edilememektedir. İmplant ve sinüs lift çalışmaları dünyada domuzlar üzerinde yapılmaktadır. Domuzlar bölgenin anatomisi ve büyüklüğü açısından insana oldukça benzer bir çalışma modeli olarak görev yapmaktadır. ${ }^{51}$ Ülkemizde domuzlar ile çalışılabilecek deney hayvanları laboratuarı oldukça kısıtlı olması nedeniyle sıklıkla implant konulu çalışmalarda tavşanlar tercih edilmektedir. Tavşanların femur veya tibiasına yerleştirilen gerçek boyda implantlarda yüzey özellikleri ${ }^{42,52}$, primer stabilite ${ }^{53}$, osseointegrasyon ${ }^{54}$,implant başarısi ${ }^{55,56}$ ve sistemik koşulların etkisi gibi birçok konu incelenebilmektedir. ${ }^{57}$ Ayrıca ileri cerrahi tekniklerin pratiğinde hayvan modelleri kulanılmaktadır. ${ }^{58}$

Tablo 1. Periodontoloji çalışmalarında kullanılan deney hayvanı modellerinin uygunluğu.

\begin{tabular}{|c|c|c|c|c|c|}
\hline $\begin{array}{l}\text { Hayvan } \\
\text { Modelleri }\end{array}$ & $\begin{array}{c}\text { Hastalık } \\
\text { Etiyolojisi }\end{array}$ & \begin{tabular}{|l|} 
Diş \\
Taşı \\
\end{tabular} & $\begin{array}{c}\text { İmmunoloji ve } \\
\text { Mikrobiyoloji }\end{array}$ & Biyomateryalle & mplan \\
\hline $\begin{array}{c}\text { Insan Olmayan } \\
\text { Primat } \\
\end{array}$ & ++++ & ++ & ++++ & ++++ & +++ \\
\hline Köpek & +++ & +++ & +++ & ++++ & ++++ \\
\hline Tavşan & + & + & + & ++ & ++ \\
\hline Feret & ++ & +++ & + & + & + \\
\hline Rat & + & ++ & +++ & ++ & + \\
\hline Hamster & + & ++ & +++ & + & + \\
\hline
\end{tabular}

\section{SONUÇ}

Deney hayvan modeli hazırlanırken, araştırmacının çalışacağı konu üzerine uygun hayvanı ve defekt modelini seçebilmesi için yeterli bilgi ve birikime sahip olması gerekir. Sonuç olarak çalışılan hayvan modelinin uygun seçimi için hayvanın özellikleri dikkatle incelenerek, çalışılacak konuya uygun olan hayvan seçilmelidir.
NOT: Çalışmada herhangi bir yazar, kurum ya da kuruluş ile çıkar çatışması içerisinde bulunmamaktadır. Makale daha önce hiçbir yerde yayınlanmamış ve yayınlanmak üzere işlem görmemektedir

\section{KAYNAKLAR}

1. Struillou $X$, Boutigny $H$, Soueidan A, Layrolle P. Experimental Animal Models in Periodontology: A Review. Open Dent J 2010; 4:37-47.

2. Bhardwaj A, Bhardjaw S. Contribution of Animal Models in Periodontal Research. IJAVMS 2012; 6:150-7.

3. $\mathrm{Oz} \mathrm{H}$, Puleo DA. Animal Models for Periodontal Disease. J Biomedi Biotechnology 2011; 2011: 8.

4. Kantarcı A, Hasturk $H$, van Dyke TE. Animal Models for Periodontal Regeneration and Peri-implant Responses. Periodontology 2000 2015; 68:68-82.

5. Navia JM. Animal Models in Dental Research, University, Ala.: University of Alabama Press; 1977, p. 466.

6. Guessous F, Huynh C, N'Guyen H, et al. An Animal Model for the Assessment of Gingival Lesions. ] Pharmacol Toxicological Method 1994; 32:161-7.

7. Craig RG, Kamer AR, Kallur SP, Inoue M, Tarnow DP. Effects of Periodontal Cell Grafts and Enamel Matrix Proteins on The Implant-Connective Tissue Interface: A Pilot Study in the Minipig. J Oral Implantology 2006; 32:228-36.

8. Graves DT, Fine D, Teng YT, Van Dyke TE, Hajishengallis G. The Use of Rodent Models to Investigate Host-Bacteria Interactions Related to Periodontal Diseases. J Clinical Periodontol 2008; 35:89-105.

9. Yamasaki A, Nikai H, Niitani K, Ijuhin N. Ultrastructure of the Junctional Epithelium of Germfree Rat Gingiva. J Periodontol 1979; 50:641-8.

10. Listgarten MA. Similarity of Epithelial Relationships in the Gingiva of Rat and Man. J Periodontol 1975; 46:677-80.

11. Page RC, Schroeder HE. Periodontitis in Man and Other Animals: A Comparative Review: 1 ed. S. karger; 1982.

12. Arabaci T, Kermen E, Ozkanlar S, et al. Therapeutic Effects of Melatonin on Alveolar Bone Resorption After Experimental Periodontitis in Rats: A Biochemical and Immunohistochemical Study. J Periodontol 2015; 86:874-81.

13. Kose O, Arabaci T, Kara A, et al. Effects of Melatonin on Oxidative Stress Index and Alveolar Bone Loss in Diabetic Rats With Periodontitis. J Periodontol 2016; 87:82-90. 
14. Kose $\mathrm{O}$, Arabaci $\mathrm{T}$, Yemenoglu $\mathrm{H}$, et al. Influences of Fucoxanthin on Alveolar Bone Resorption in Induced Periodontitis in Rat Molars. Marine drugs 2016; 14.

15. Klausen B. Microbiological and Immunological Aspects of Experimental Periodontal Disease in Rats: A Review Article. J Periodontol 1991; 62:5973.

16. Irving JT, Socransky SS, Heeley JD. Histological Changes in Experimental Periodontal Disease in Gnotobiotic Rats and Conventional Hamsters. J Periodontal Res 1974; 9:73-80.

17. Baer PN, Stephan RM, White CL. Studies on Experimental Calculus Formation in the Rat I. Effect of Age, Sex, Strain, High Carbohydrate, High Protein Diets. J Periodontol 1961; 32:190-6.

18. Heijl L, Wennstrom J, Lindhe J, Socransky SS. Periodontal Disease in Gnotobiotic Rats. J Periodontal Res 1980; 15:405-19.

19. Weinberg M, Bral M. Laboratory Animal Models in Periodontology. J Clin Periodontol 1999; 26:33540.

20. Huang KK, Shen C, Chiang CY, Hsieh YD, Fu E. Effects of Bone Morphogenetic Protein-6 on Periodontal Wound Healing in A Fenestration Defect of Rats. J Periodontal Res 2005; 40:1-10.

21. Nemcovsky CE, Zahavi S, Moses O, et al. Effect of Enamel Matrix Protein Derivative on Healing of Surgical Supra-Infrabony Periodontal Defects in the Rat Molar: A Histomorphometric Study. J Periodontol 2006; 77:996-1002.

22. Stavropoulos A, Kostopoulos L, Nyengaard JR, Karring T. Deproteinized Bovine Bone (Bio-Oss) and Bioactive Glass (Biogran) Arrest Bone Formation When Used As An Adjunct to Guided Tissue Regeneration (GTR): An Experimental Study in the Rat. J Clin Periodontol 2003; 30:636-43.

23. Donos N, Sculean A, Glavind L, Reich E, Karring T. Wound Healing of Degree III Furcation Involvements Following Guided Tissue Regeneration and/or Emdogain. A Histologic Study. J Clin Periodontol 2003; 30:1061-8.

24. Donos N, Glavind L, Karring T, Sculean A. Clinical Evaluation of An Enamel Matrix Derivative in the Treatment of Mandibular Degree II Furcation Involvement: A 36-Month Case Series. Int J Periodont Rest 2003; 23.

25. Eggert FM, Germain JP, Cohen B. The Gingival Epithelium of Rodent Molars With Limited Eruption. Acta anatomica 1980; 107:297-306.

26. Lallam-Laroye C, Escartin Q, Zlowodzki AS, et al.
Periodontitis Destructions Are Restored by Synthetic Glycosaminoglycan Mimetic. J Biomed Mater Res A 2006; 79:675-83.

27. Baron R, Saffar J-L. A Quantitative Study of Bone Remodeling During Experimental Periodontal Disease in the Golden Hamster. J Periodontal Res 1978; 13:309-15.

28. Enwonwu CO. Interface of Malnutrition and Periodontal Diseases. Am J Clin Nutr 1995; 61:430-6.

29. Kowashi Y, Jaccard F, Cimasoni G. Sulcular Polymorphonuclear Leucocytes and Gingival Exudate During Experimental Gingivitis in Man. J Periodontal Res 1980; 15:151-8.

30. Cutress TW. Histopathology of Periodontal Disease in Sheep. J Periodontol 1976; 47:643-50.

31. Tyrrell KL, Citron DM, Jenkins JR, Goldstein EJ. Periodontal Bacteria in Rabbit Mandibular and Maxillary Abscesses. J Clin Microbiol 2002; 40:1044-7.

32. Aaboe M, Pinholt EM, Hjorting-Hansen E. Unicortical Critical Size Defect of Rabbit Tibia is Larger Than 8 Mm. J Craniofac Surg 1994; 5:201-3.

33. Schmitt JM, Buck DC, Joh SP, Lynch SE, Hollinger JO. Comparison of Porous Bone Mineral and Biologically Active Glass in Critical-Sized Defects. J Periodontol 1997; 68:1043-53.

34. Oortgiesen DA, Meijer GJ, Bronckers AL, Walboomers XF, Jansen JA. Fenestration Defects in the Rabbit Jaw: An Inadequate Model for Studying Periodontal Regeneration. Tissue Eng Part C Methods 2010; 16:133-40.

35. Takahashi D, Odajima T, Morita M, Kawanami M, Kato $H$. Formation and Resolution of Ankylosis Under Application of Recombinant Human Bone Morphogenetic Protein-2 (Rhbmp-2) to Class III Furcation Defects in Cats. J Periodontal Res 2005; 40:299-305.

36. Anthony J, Waldner C, Grier C, Laycock AR. A Survey of Equine Oral Pathology. J Vet Dent 2010; 27:12-5.

37. Schliephake H, Aleyt J. Mandibular Onlay Grafting Using Prefabricated Bone Grafts with Primary Implant Placement: An Experimental Study In Minipigs. Int J Oral \& Maxillofac Imp 1998; 13:38493.

38. Romanos GE, Henze M, Banihashemi S, Parsanejad HR, Winckler J, Nentwig GH. Removal of Epithelium in Periodontal Pockets Following Diode (980 Nm) Laser Application in the Animal Model: An in Vitro Study. Photomed Laser Surg 2004; 22:177-83. 
39. Zhang Y, Miron RJ, Li S, Shi B, Sculean A, Cheng $X$. Novel Mesoporous Bioglass/Silk Scaffold Containing Adpdgf-B and Adbmp7 for the Repair of Periodontal Defects in Beagle Dogs. J Clin Periodontol 2015; 42:262-71.

40. Gu XQ, Li YM, Guo J, Zhang LH, Li D, Gai XD. Effect of Low Intensity Pulsed Ultrasound on Repairing the Periodontal Bone of Beagle Canines. Asian Pacific J Tropical Med 2014; 7:325-8.

41. Nagayasu-Tanaka T, Anzai J, Takaki S, et al. Action Mechanism of Fibroblast Growth Factor-2 (FGF-2) in the Promotion of Periodontal Regeneration in Beagle Dogs. PloS one 2015; 10: e0131870.

42. Huang Z, Wang Z, Li C, Yin K, Hao D, Lan J. Application of Plasma Sprayed Zirconia Coating in Dental Implant: Study in Implant. J Oral Implantol 2018.

43. Jing D, Yan Z, Cai J, et al. Low-1 Level Mechanical Vibration Improves Bone Microstructure, Tissue Mechanical Properties and Porous Titanium Implant Osseointegration by Promoting Anabolic Response in Type 1 Diabetic Rabbits. Bone 2018; 106:11-21.

44. Pforringer D, Harrasser N, Muhlhofer $\mathrm{H}$, et al. Osteoinduction and Conduction Through Absorbable Bone Substitute Materials Based on Calcium Sulfate: In Vivo Biological Behavior in A Rabbit Model. J Mater Sci Mater Med 2018; 29:17.

45. Johnson-Delaney CA. Anatomy and Disorders of the Oral Cavity of Ferrets and Other Exotic Companion Carnivores. Vet Clin North Am Exot Anim Pract 2016; 19:901-28.

46. Triantafyllou A, Harrison JD, Garrett JR. Microliths in the Parotid of Ferret Investigated by Electron Microscopy and Microanalysis. Int J Clin Exp Pathol 2009; 90:439-47.

47. Chen CK, Chang NJ, Wu YT, et al. Bone Formation Using Cross-Linked Chitosan Scaffolds in Rat Calvarial Defects. Eur J Oral Sci 2018; 27:15-21.

48. Wang S, Noda K, Yang Y, Shen Z, Chen Z, Ogata $Y$. Calcium hydroxide regulates transcription of the bone sialoprotein gene via a calcium-sensing receptor in osteoblast-like ROS 17/2.8 cells. Eur J Oral Sci 2018; 126:13-23.

49. Fernandes LA, Martins TM, de Almeida JM, Theodoro LH, Garcia VG. Radiographic Assessment of Photodynamic Therapy As An Adjunctive Treatment on Induced Periodontitis in Immunosuppressed Rats. J Applied Oral Sci 2010; 18: 237-43.
50. Matheus HR, Ervolino E, Faleiros PL, et al. Cisplatin Chemotherapy Impairs the Peri-Implant Bone Repair Around Titanium Implants: An in Vivo Study in Rats. J Clin Periodontol 2018; 45:241-52.

51. Matys J, Flieger R, Dominiak M. Effect of Diode Lasers with Wavelength of 445 And $980 \mathrm{Nm}$ on A Temperature Rise When Uncovering Implants for Second Stage Surgery: An Ex-Vivo Study in Pigs. Adv Clin Exp Med 2017; 26:687-93.

52. Johansson P, Barkarmo S, Hawthan M, Peruzzi N, Kjellin $P$, Wennerberg A. Biomechanical, Histological and Computed X-Ray Tomographic Analyses of Hydroxyapatite Coated PEEK Implants in An Extended Healing Model in Rabbit. J Biomed Mater Res A 2018; 106:1440-7.

53. Ademhan O, Kucukkurt S, Cetiner S. Biomechnical Comprasion of Stresses Generated Through Two Different Dental Implants Designs to Be Applied in Augmented Maxillary Sinus. J Dent Fac Atatürk Uni 2017; 27:154-60.

54. AlFarraj $A A$, Sukumaran A, Al Amri MD, Van Oirschot $A B$, Jansen JA. Erratum to: A Comparative Study of the Bone Contact to Zirconium and Titanium Implants After 8 Weeks of Implantation in Rabbit Femoral Condyles. Odontology 2018; 106:37-44.

55. Kürkçüoğlu I, Köroğlu A, Özkır SE. Dental Implantlarda Başarı Kriterleri ve Başarı Değerlendirme Yöntemleri. Atatürk Üniv Diş Hek Fak Derg 2010; 20:221-9.

56. Balcı Yüce H. Periodontoloji Alanında Hayvan Çalışmaları: Deneysel Periodontal ve Periimplant Hastalığın İndüksiyonu. Cumhuriyet Dent J 2016; 20:62-71.

57. Kim HS, Lee JI, Yang SS, Kim BS, Kim BC, Lee J. The Effect of Alendronate Soaking and Ultraviolet Treatment on Bone-Implant Interface. Clin Oral Implants Res 2017; 28:1164-72.

58. Çakir M, İnci K. İmplant uygulamaları için kret koruma teknikleri. Atatürk Üniv. Diş Hek Fak Derg 2015; 25:107-18.
Yazışma Adresi
Dr. Öğr. Üyesi Mustafa Özay Uslu
Department of Periodontology,
Faculty of Dentistry,
Inonu University, 44280, Malatya/Turkey
Telephone: +90422 341 1100/6252
Fax: 04223411107
E-mail: mustafaozayuslu@hotmail.com 